\title{
REVIEW
}

\section{MUC1 and MUC2 in pancreatic neoplasia}

\author{
E Levi, D S Klimstra, N V Adsay, A Andea, O Basturk
}

J Clin Pathol 2004;57:456-462. doi: 10.1136/jcp.2003.013292

MUCs are glycoproteins with various roles in homeostasis and carcinogenesis. Among other actions, $\mathrm{MUCl}$ may inhibit cell-cell and cell-stroma interactions and function as a signal transducer, participating in cancer progression. In contrast, MUC2 is normally found only in goblet cells, where it contributes to the protective barrier function of these cells. Recently, a tumour suppressor role has been demonstrated for MUC2, and both MUC1 and MUC2 appear to have important roles in pancreatic neoplasia. $\mathrm{MUCl}$ appears to be a marker of aggressive phenotype and may facilitate the vascular spread of carcinoma cells. In contrast, MUC2 is rarely detectable in aggressive pancreatic tumours, but is commonly expressed in intraductal papillary mucinous neoplasms (IPMNs), which are rare, indolent tumours, in intestinal IPMNs, and in indolent colloid carcinomas. MUC2 appears to be not only a marker of this indolent pathway, but also partly responsible for its less aggressive nature. Thus, in pancreatic neoplasia, $\mathrm{MUC1}$ and MUC2 have potential diagnostic and prognostic value as markers of aggressive and indolent phenotypes, respectively, and have potential as therapeutic targets.

See end of article for authors' affiliations

Correspondence to:

Correspondence to:
Dr N V Adsay, Harper University Hospital, Wayne State University Medical School, Department of Pathology, 3990 John R, Detroit, MI 48201, USA

adsayv@med.wayne.edu

Accepted for publication 22 September 2003
M UCs are a heterogeneous group of glycoproteins with various roles both in homeostasis and carcinogenesis. MUC1, also referred to as mammary-type mucin, has a role in the maintenance of the lumina of ductal epithelial cells, and is thought to have an inhibitory role in cell-cell and cell-stroma interactions and in cytotoxic immunity. It also appears to function as a signal transducer, closely interacting with the epidermal growth factor receptor (EGFR) family, and participating in the progression of carcinogenesis.

\section{"Both MUC1 and MUC2 seem to have important roles in pancreatic neoplasia"}

In contrast, MUC2 is referred to as intestinaltype mucin because its expression is normally limited to goblet cells, where it contributes to the protective barrier function of these cells. Recently, MUC2 has been shown to have tumour suppressor activity, as demonstrated by the neoplastic transformation seen in the gastrointestinal system of MUC2 knockout mice. Both MUC1 and MUC2 seem to have important roles in pancreatic neoplasia. MUCl appears to be a marker of aggressive phenotype. It is commonly expressed in high grade but not low grade pancreatic intraepithelial neoplasia (PanIN; microscopic/incidental precursors of invasive carcinoma). Furthermore, it is abundant in almost all examples of conventional ductal adenocarcinoma. In fact, dense cytoplasmic immunostaining for MUCl can be used as a diagnostic tool, because such staining is not usually seen in normal or preinvasive neoplasia or other carcinoma types in this region. This may also be helpful in the subclassification of ampullary neoplasia. It is also possible that MUCl facilitates the vascular spread of carcinoma cells by helping them to remain detached from the endothelial cells.

In sharp contrast to MUC1, MUC2 is almost never detectable in PanINs or conventional adenocarcinomas, but instead, it is commonly expressed in a rare but distinctive set of tumours that appear to form a distinct and indolent pathway of carcinogenesis. These are intraductal papillary mucinous neoplasms (IPMNs), characterised by clinically detectable papillary tumours that grow within and lead to pronounced cystic dilatation of the ducts (mass forming preinvasive neoplasia). MUC2 is expressed consistently in the intestinal subset of IPMNs, which is morphologically similar to villous adenoma. MUC2 is also uniformly present in colloid carcinoma, an indolent form of invasive carcinoma, which often arises in association with IPMN. MUC2 may not only be a marker of this indolent pathway, but may also partly be responsible for its less aggressive nature. It is speculated that MUC2, also known as gel forming mucin, may be a key factor in the slow growth of colloid carcinoma cells by forming a protective gel around the neoplastic cells, and therefore leading to the characteristic "cells floating in abundant mucin" morphology, and also limiting the spread of the cells.

Thus, in pancreatic neoplasia, MUCl and MUC2 may have diagnostic and prognostic value as markers (and possible instigators) of the aggressive and indolent phenotypes, respectively, and may have potential as therapeutic targets.

\section{MUC 1 AND MUC2: BIOCHEMICAL AND PHYSIOLOGICAL PROPERTIES}

Mucins are the major components of mucous, the visco-elastic substance that protects and lubricates epithelial mucosa, including that of the gastrointestinal tract. They are highly

Abbreviations: EGFR, epidermal growth factor receptor; IPMN, intraductal papillary mucinous neoplasia; MAPK, mitogen activated protein kinase; PanIN, pancreatic intraepithelial neoplasia; TCF, T cell factor 
glycosylated molecules; up to $80 \%$ of their mass consists of $O$-linked glycosyl residues. ${ }^{12}$ Mucins constitute an expanding family of proteins that can be grouped into "transmembrane mucins" and "secretory mucins". 3 So far, 19 different mucin apoproteins have been identified. ${ }^{3-6}$ The transmembrane mucins are emerging as signal transducer proteins that regulate the growth, adhesion, and motility of cells. ${ }^{25} 7$

The best studied transmembrane mucin is MUCl, also known as epithelial membrane antigen, which was first identified in human milk. ${ }^{2}$ MUCl is synthesised as a single polypeptide that undergoes proteolytic cleavage, creating a heterodimer that remains associated during its post-translational processing in the Golgi. The larger component contains most of the extracellular domain-the tandem repeat domain-which comprises 30-90 repeat sequences of 20 amino acids. Approximately $50-90 \%$ of the mass of MUCl results from the $O$-glycosylation that occurs on the amino acid repeat units. The smaller component of the heterodimer consists of an extracellular stem that joins the larger component to the transmembrane domain and a 72 amino acid cytoplasmic tail, which has signal transduction properties as a result of the presence of docking sites for $\mathrm{SH} 2$ domain containing proteins, in addition to the presence of tyrosine phosphorylation sites. ${ }^{8-10}$

MUCl is expressed by almost all human glandular epithelial tissues and throughout all regions of the gastrointestinal tract. $^{271112} \mathrm{MUCl}$ is also expressed in normal pancreatic intralobular ducts, together with MUC5AC, MUC5B, and MUC6. ${ }^{73-17}$ One major role of the MUC1 protein is to act as an anti-adhesive protein to maintain the luminal integrity of the lining epithelium. ${ }^{58}$ Therefore, in normal epithelia its expression is largely limited to the apical membrane of the cells.

In contrast, MUC2 is a secreted form of mucin, which is exclusively expressed in the goblet cells lining the gastrointestinal mucosa. MUC2 is characterised by tandem and irregular repeat sequences rich in threonine and serine, which are sites of attachment of the oligosaccharide chains. The MUC2 gene product is more than 5100 amino acids long in its most common allelic form, which accounts for one fifth of the mucin glycoprotein molecule by weight. The MUC2 protein is polymerised end to end through disulfide bridges to form large secreted polymeric gel forming mucins. It acts as a protective barrier at mucosal surfaces. ${ }^{18-20}$ It is also expressed in areas of intestinal metaplasia, such as those seen in Barrett's oesophagus and long standing Helicobacter pylori gastritis. ${ }^{21-23}$ MUC2 is not expressed in the normal pancreas. ${ }^{24}$

\section{MUC1 AND MUC2: THEIR POSSIBLE ROLES IN MOLECULAR CARCINOGENESIS}

MUCl is a signal transducer molecule, which can sense environmental changes and transduce messages into the cell. It is normally expressed on the apical borders of secretory epithelial cells. However, in tumour cells, MUCl expression loses its polarity, being expressed throughout the entire cell surface. ${ }^{25} 25$ The presence of extracellular, transmembrane, and cytoplasmic domains makes it an ideal candidate as a signal transduction unit. ${ }^{25} 81025-27$

MUCl has been shown to be associated with the epidermal growth factor receptor (EGFR) members EGFR, ErbB2 (HER2/neu), ErbB3, and ErbB4 receptor tyrosine kinases through its cytoplasmic tail. ${ }^{1027-29}$ In addition, binding of Grb2/sos and c-src to the cytoplasmic tail of MUC1 has been demonstrated..$^{27}$ These findings suggest that the Ras-Rafmitogen activated protein kinase (MAPK) signalling system can be triggered by MUC1. The importance and the context of these interactions are not completely clear. It is tempting to speculate that the extracellular domain of the MUCl protein can sense some distinct changes in the extracellular environment, such as adhesion status or chemical composition of the milieu (for example, the presence of oxygen radicals). ${ }^{8}$

In addition to binding to EGFR family members, MUC1 can physically interact with $\beta$ catenin, a key molecule of the Wnt signalling pathway, and also a key molecule in colorectal tumorigenesis. $^{10262930} \beta$ Catenin is normally bound to cadherins, which regulate cell to cell adhesion. Upon activation of the Wnt pathway, $\beta$ catenin translocates to the nucleus, binding the lymphoid enhancer $1 / T$ cell factor (TCF) complex, thereby initiating the transcription of growth promoting genes. $.^{10}{ }^{18} 28-30 \mathrm{MUCl}$ is associated with increased nuclear localisation of $\beta$ catenin. In fact, Wen et al recently demonstrated the translocation of the cytoplasmic tail of MUCl to the nucleus in conjunction with $\beta$ catenin. ${ }^{31}$ These findings suggest that, overall, MUCl is associated with the detachment of $\beta$ catenin from the cadherins and its translocation to the nucleus. This translates into loss of adhesion, and perhaps contact inhibition, and increased proliferation.

\section{"In addition to binding to epidermal growth factor receptor family members, MUC1 can physically interact with $\beta$ catenin, a key molecule of the Wnt signalling pathway, and also a key molecule in colorectal tumor- igenesis"}

The association of MUCl with the cadherin-catenin-TCF and EGFR-Raf-Ras-MAPK, signalling pathways, two important transduction modules that regulate cell proliferation and diverse functions, strongly suggests that MUCl has an active and functional role in carcinogenesis in a variety of tissues. MUCl is overexpressed and differentially glycosylated by many tumours. There are several studies demonstrating the adverse prognostic effect of MUCl expression on survival in various tumours, including those of the stomach, breast, kidney, colon, endometrium, lung, bile duct, and even lymphomas. ${ }^{32-44}$ In a recent study, MUCl tandem repeats of the extracellular portion and the cytoplasmic tail were shown to be responsible for the invasive properties of a pancreatic carcinoma cell line. ${ }^{45}$

In contrast to MUC1, MUC2 has no transmembrane domain or signal transduction properties. Recently, there has been increased interest in the MUC2 protein as the result of the demonstration that MUC2 knockout mice develop colorectal tumours, including tubular and villous adenomas and invasive carcinomas. ${ }^{46}$ This finding indicates that MUC2 has tumour suppressor properties.

The expression of MUC2 is regulated by homeobox genes CDX1 and CDX2. ${ }^{47-49}$ These transcription factors are key in understanding normal intestinal development and the intestinal metaplasia that is often seen in $H$ pylori gastritis, Barrett's oesophagus, and cholecystitis. ${ }^{50-53}$ In fact, it has been shown that intestinal metaplasia of the stomach is always preceded by activation of the transcription factor CDX2. ${ }^{48}$ CDX2 expression also precedes the expression of MUC2 in Barrett's epithelium..$^{53}$ In a recent study by Seno et al, CDX2 expression in gastric cancer was associated with intestinaltype gastric cancer, a lower proliferation rate, and better survival compared with non-expressors. ${ }^{50}$ By binding to enhancer sequences in the promoter regions of target genes, CDX2 triggers the transcription of genes that encode intestine specific proteins, such as MUC2, sucrase/isomaltase, lactase, villin, KLF4, and carbonic anhydrase I. CDX2 also upregulates its own expression. Another way that CDX2 promotes intestinal differentiation is by upregulating the expression of WAF1/p21, causing cell cycle arrest. ${ }^{54}$ Overall, CDX2 seems to 

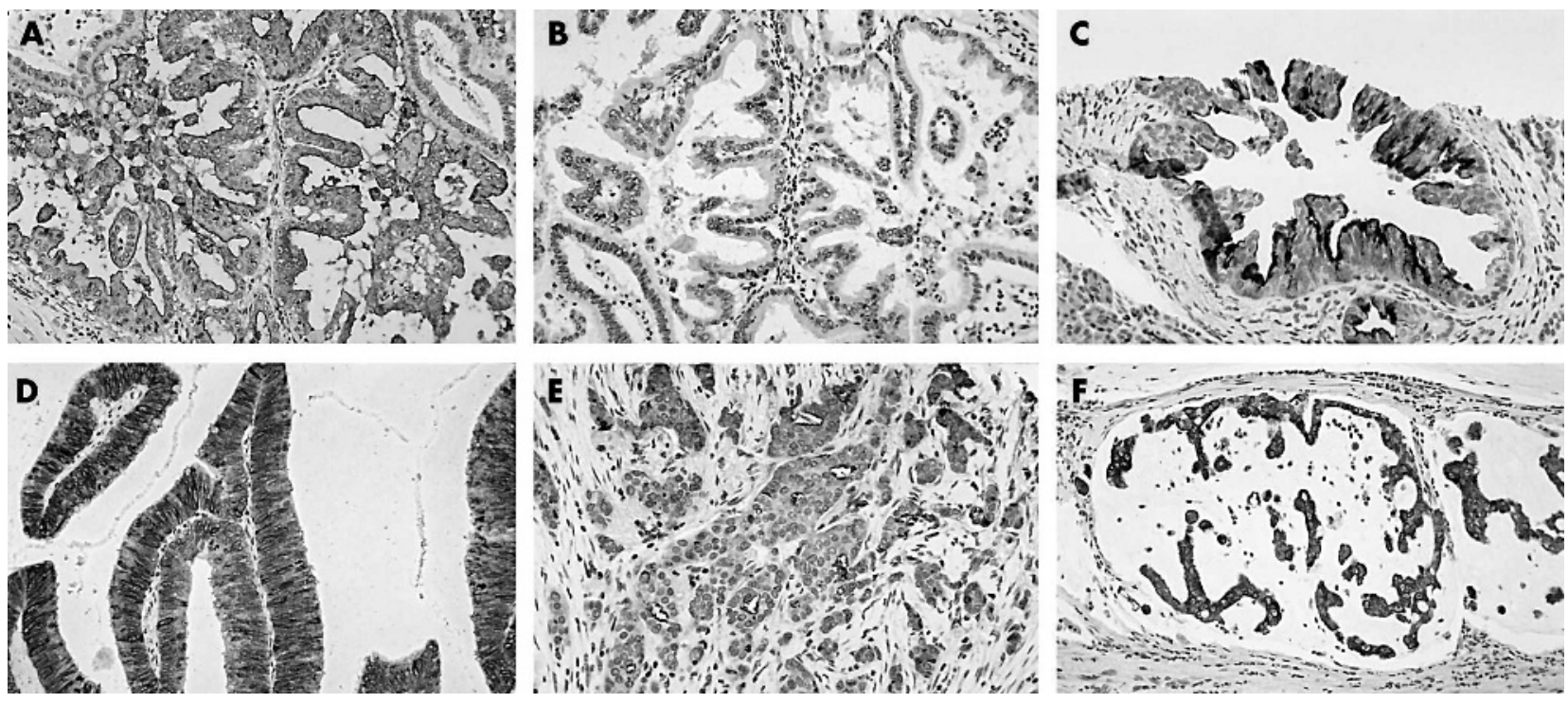

Figure $1 \mathrm{MUC1}$ and MUC2 staining of different entities. (A) MUC1 staining of an intraductal papillary mucinous neoplasm (IPMN), pancreatobiliary type; original magnification, $\times 100$ ). (B) Lack of MUC2 staining of the same lesion; original magnification, $\times 100$. (C) MUC1 staining of a grade 3 pancreatic intraepithelial neoplasia lesion; original magnification, $\times 100$. (D) MUC2 staining of a villous intestinal-type IPMN; original magnification, $\times 200$. (E) MUC1 staining of a ductal-type pancreatic adenocarcinoma; original magnification, $\times 100$. (F) MUC2 staining of a colloid carcinoma of the pancreas; original magnification, $\times 100$.

promote the differentiation and maintenance of intestinal epithelial cells. ${ }^{54}$

MUC2 expression is also regulated by $\mathrm{p} 53 .{ }^{55}$ The MUC2 gene has been shown to have p53 binding sites. ${ }^{55}$ In cellular stress conditions, p53 is activated to control cell proliferation and allow DNA repair. ${ }^{56}$ It also triggers apoptosis when the repair efforts have been futile. ${ }^{56}$ The fact that p53 triggers MUC2 expression suggests that MUC2 is part of a stress response programme. ${ }^{55}$ Because MUC2 is part of the intestinal metaplasia programme, which itself is a response to stress conditions in gastric, oesophageal, and biliary mucosa, MUC2 expression may not be an oncogenic event per se, but a protective mechanism, which is activated to prevent further exposure to carcinogens. ${ }^{54}$ However, overall, the development of intestinal metaplasia in the stomach and oesophagus is associated with an increased risk of cancer. $^{54} 5758$

Whereas mucin secretion and MUC2 expression are part of the many stress responses in airway epithelia, stomach, and biliary tract, conversely, loss of MUC2 expression is a frequent feature of colorectal cancer. ${ }^{46}{ }^{59-61}$ In fact, during colorectal cancer progression, loss of mucin and MUC2 expression are seen frequently, and are followed by overexpression of MUCl..$^{606} 63$

In many tissues, loss of MUC2 gene activation has been attributed to receptor methylation. ${ }^{24596465}$ Siedow et al have studied the mechanism of MUC2 expression in pancreatic carcinoma cell lines. They have shown that in non-expressor cell lines the MUC2 gene is methylated, whereas in the expressors it is demethylated. The investigators also treated non-expressor cell lines with demethylating agents, such as 5-aza-2-deoxycytidine, which caused expression of MUC2 in non-expressors. ${ }^{24}$ Demethylating agents may be useful as potential therapeutic agents in treating aggressive adenocarcinomas.

\section{MUC1 AND MUC2 EXPRESSION IN NORMAL ADULT PANCREAS}

In the normal adult pancreas, MUCl expression is confined to the apical membrane of intralobular ductules, possibly a manifestation of the "lumen maintenance" role of MUCl.
MUCl expression is not detected in larger ducts or other pancreatic elements (islets or acini). ${ }^{66}{ }^{67}$ It should be noted here that, in our opinion, it is these intralobular ductules that pancreatic ductal adenocarcinoma resembles most closely, both in its histochemical properties and its immunophenotype.

MUC2 is not expressed in normal adult pancreas. ${ }^{66} 67$

\section{MUC1 AND MUC2 IN PREINVASIVE NEOPLASIA OF THE PANCREAS}

Pancreatic intraepithelial neoplasia

- MUCl: expressed in some PanIN-3 tumours only

- MUC2: virtually absent

PanIN is the term adopted recently for the microscopic/ incidental form of intraductal proliferations that have been long suspected to be the precursors of invasive ductal adenocarcinoma. ${ }^{68}$ These proliferations have been previously classified under various names ranging from metaplasia (for the early forms) to hyperplasia (with or without atypia) to dysplasia. ${ }^{69-71}$ According to the scheme proposed recently, these lesions are unified under the term PanIN (to conform with the terminology used in other organs, such as the prostate), and classified into three grades: PanIN-1 includes but is not limited to changes previously regarded as mucinous metaplasia (but which were recently found to harbour several molecular alterations associated with neoplasia), and at the other end of the spectrum, PanIN-3, which includes carcinoma in situ. ${ }^{68}$

MUCl is expressed in a substantial number of PanIN-3 tumours but is almost absent in PanIN-1 or PanIN-2 (fig lC). In contrast, MUC2 is not detected in PanINs. ${ }^{66}$

\section{Intraductal papillary mucinous neoplasia \\ - MUC1: rarely expressed \\ - MUC2: very frequently expressed}

IPMN is now a well recognised category in the pancreas, unifying tumours that are characterised by intraductal proliferation of neoplastic mucinous cells, which often form papillae, and lead to cystic dilatation of the pancreatic ducts, 
forming clinically and macroscopically detectable masses. ${ }^{72-79}$ These tumours have previously been reported under a variety of names, such as villous adenoma, intraductal papillary tumour, mucin producing tumour, mucinous duct ectasia, etc. ${ }^{80-83}$ IPMN should be distinguished from the more widely recognised mucinous cystic neoplasms (see below).$^{84-86}$

Similar to PanINs, IPMNs are regarded as a form of preinvasive neoplasia, acting as a precursor and maybe as even a marker of invasive carcinoma. ${ }^{87-89}$ Both PanINs and IPMNs are intraductal lesions with papilla forming mucinous cells; however, in the case of IPMNs, the proliferation progresses to form large (clinically and grossly detectable) cystic or papillary masses, whereas PanINs are noted only as incidental findings. ${ }^{66} 90$ We think that this dichotomy represents two relatively distinct pathways of carcinogenesis, although there are some overlaps, as would be expected. This dichotomy is similar to that seen in other organs, such as: (1) in the urothelium, as flat versus papillary transitional cell carcinomas; or (2) in the breast, as intracystic papillary carcinoma versus ordinary intraductal proliferations; these are distinct pathways not only clinically and morphologically, but also biologically and at the molecular level. ${ }^{.1-94}$

"MUC expression patterns not only support the dichotomy between pancreatic intraepithelial neoplasia and intraductal papillary mucinous neoplasia (IPMN) but also confirm the existence of morphological subtypes in IPMN"

MUCl and MUC2 expression patterns in IPMNs versus PanINs support this dichotomy. Whereas MUC2 expression is almost absent in PanINs, it is present in a substantial number of IPMNs. ${ }^{66}$ In particular, MUC2 expression is uniformly diffuse and strong in the most common subtype of IPMN (fig 1C), which is described as villous/intestinal type or compact cell type, and is characterised by finger-like papillary projections that are lined by columnar cells with cigar shaped nuclei, and is morphologically very similar to colonic villous adenomas. In contrast, MUCl, which is often present in PanIN-3, is much less frequently expressed in IPMNs. ${ }^{33} 66$ More interestingly, those IPMNs that express MUCl are invariably of the rare subtype that we have been independently referring to as pancreatobiliary, and which is characterised by more complex (arborising) papillae and cuboidal cells, similar to those seen in biliary papillomatosis (fig 1A, B). This differential expression of MUC1 and MUC2 in the subtypes of IPMN has been noted by various investigators, including Luttges et al, ${ }^{95}{ }^{96}$ Kloppel et al, ${ }^{97}$ and Yonezawa et al, ${ }^{33}$ who refer to these subtypes as dark cell, clear cell, and compact cell types. Because MUC2 is also referred to as intestinal type mucin and regarded as a marker of goblet cells, its consistent expression in the intestinal subtype of IPMN can be taken as further evidence of intestinal differentiation. In other words, MUC expression patterns not only support the dichotomy between PanINs and IPMNs but also confirm the existence of morphological subtypes in IPMNs.

\section{Intraductal oncocytic papillary neoplasia (IOPN) \\ - MUC1: expressed (data limited) \\ - MUC2: expressed (data limited)}

Oncocytic papillary tumours are characterised by mucin filled cysts containing nodular papillary projections. Dilated ducts communicating with the main tumour can also be seen. Microscopically, the cystic structures correspond to dilated ducts containing intraductal tumour. The tumours are characterised by variably complex, arborising papillary structures. The papillae have thin, delicate fibrovascular cores with focal myxoid changes, and are lined by stratified oncocytic cells. Goblet cells and intraepithelial mucin containing lumina are also present, with these last structures resulting in a characteristic cribriform pattern. The extent of epithelial proliferation varies from case to case and between different regions within individual tumours; solid sheets of cells can often be identified. ${ }^{73}$ Intraductal oncocytic papillary neoplasms have been studied for their mucin expression patterns and they were found to express both MUCl and MUC2 by Luttges et al. ${ }^{95}$ However, Terris et al reported that oncocytic papillary neoplasms lacked MUC2 expression. ${ }^{16}$ Because they are rarely encountered, there is still a need for further work on these tumours.

\section{Mucinous cystic neoplasms}

- MUC1: rarely expressed

- MUC2: present only in goblet cells; no diffuse labelling

Mucinous cystic neoplasms are seen typically in perimenapausal women ( $>95 \%$ women; mean age, 50 years) and present as multilocular, thick walled cysts in the tail of the pancreas. Ovarian-like stroma is invariably present..$^{87}$ Luttges et al have studied the mucin expression profiles of mucinous cystic neoplasms comprising adenomas, borderline lesions, and carcinomas. They found that MUC1 is not expressed in non-invasive lesions of mucinous cystic neoplasms, but is a marker of invasion. ${ }^{67}$ MUC2 expression was seen in the interspersed goblet cells. There was no diffuse staining of the lining epithelium. They found that mucinous cystic neoplasms invariably expressed MUC5AC, which is also commonly expressed in ordinary ductal carcinoma.

\section{MUC1 AND MUC2 IN INVASIVE CARCINOMAS OF THE PANCREAS \\ Conventional ductal adenocarcinomas}

- MUCl: uniform and strong expression; apical membraneous in tubule forming areas; intracytoplasmic in the poorly differentiated areas

- MUC2: virtually absent

MUCl is expressed in almost all examples of ordinary ductal (pancreatobiliary) adenocarcinomas of the pancreas, which are characterised by infiltrating small tubular units embedded in desmoplastic stroma. Expression is predominantly confined to the luminal membrane in the duct forming areas, whereas it is also intracytoplasmic in the poorly differentiated areas (fig lE)..$^{12} 456698$ MUC2 expression has been very rarely reported in ordinary ductal carcinomas of the pancreas. ${ }^{66}$

\section{Colloid carcinomas \\ - MUC1: rarely expressed \\ - MUC2: very frequently expressed}

Colloid carcinoma of the pancreas was recently described as a distinct entity and was distinguished from signet ring cell carcinomas, ordinary ductal carcinomas, and mucinous cystadenocarcinomas. ${ }^{99} 100$ Like their counterparts in the breast, colloid carcinomas of the pancreas have a much better prognosis than regular adenocarcinomas, with a five year survival of $55 \%$ compared with $10 \%$ for ordinary ductal carcinomas. ${ }^{99}$ MUC2 expression is a hallmark of colloid carcinomas of the pancreas (fig $\mathrm{lF}$ ). We recently examined the ultrastructural properties of colloid carcinomas and showed that mucin secretion was towards the stroma 


\section{Take home messages}

- MUC1 versus MUC2 staining correlates with the morphological subtypes of intraductal papillary mucinous neoplasia (IPMN) and can predict prognosis because $\mathrm{MUCl}$ expression is more often associated with pancreatobiliary-type IPMN and ductal adenocarcinoma

- If a papillary lesion has diffuse MUC2 positivity (not limited to goblet cells) it is probably an intestinal subtype of IPMN, whereas if an invasive carcinoma is positive for MUC2 staining, it is very likely to have at least a colloid carcinoma component

- MUCl is a marker of an aggressive phenotype in pancreatic intraepithelial neoplasia (PanIN): it is expressed only in PanIN grade 3 lesions and is a harbinger of invasive carcinoma

- In ampullary carcinomas, MUC1 versus MUC2 staining can help to determine the origin of the lesion: diffuse intracytoplasmic staining for $\mathrm{MUCl}$ is indicative of pancreatobiliary-type carcinoma, whereas MUC2 staining favours the intestinal type

facing surface of the cells and that extracellular mucin pools formed a barrier between the tumour cells and the stroma. This altered polarity of mucin secretion may be a contributing factor to the indolent behaviour of colloid carcinomas. ${ }^{100}$

\section{MUC1 AND MUC2 IN AMPULLARY NEOPLASIA}

- MUC1: frequently expressed in pancreatobiliary type, rarely expressed in intestinal type

- MUC2: commonly expressed in intestinal type (low sensitivity), rarely expressed in pancreatobiliary type

Ampullary carcinomas can arise from the intestinal or the pancreatobiliary epithelium. Determining the origin of adenocarcinomas arising in the papillary region is important because intestinal-type carcinomas behave like colonic adenocarcinomas, whereas pancreatobiliary types behave more like pancreatic adenocarcinomas. MUCl and MUC2 immunostaining can be helpful in determining the origin of the carcinoma, particularly when tumour histomorphology is not discriminatory, because cases with mixed patterns are frequently encountered..$^{101}{ }^{102}$ In an unpublished study, we have shown that MUCl is frequently expressed in the pancreatobiliary type, whereas MUC2 is absent. In contrast, the intestinal type lacks MUCl expression, whereas almost half of these tumours express MUC2. In other words, our preliminary unpublished data suggest that MUC1 and MUC2 are very specific in differentiating intestinal from pancreatobiliary types, whereas the sensitivity of MUC2 expression is low. In our experience, patients with ampullary carcinomas that are MUCl+/ MUC2 - have a shorter survival than patients whose tumours are MUC1-/MUC2+. ${ }^{101} 102$

\section{Authors' affiliations}

E Levi, John Dingell Veterans Administration Medical Center, 4646 John Road, Detroit, Ml 48201, USA

D S Klimstra, Memorial Sloan-Kettering Cancer Center, 1275 York Avenue, New York, NY 10021, USA

N V Adsay, A Andea, O Basturk, Harper University Hospital, 3990

John R, Detroit, MI 48201, USA

\section{REFERENCES}

1 Corfield AP, Carroll D, Myerscough N, et al. Mucins in the gastrointestinal tract in health and disease. Front Biosci 2001;6:D1321-57.

2 Gendler SJ. MUC1, the renaissance molecule. J Mammary Gland Biol Neoplasia $2001 ; 6: 339-53$.

3 Dekker J, Rossen JW, Buller HA, et al. The MUC family: an obituary. Trends Biochem Sci 2002;27:126-31.

4 Jass JR, Walsh MD. Altered mucin expression in the gastrointestinal tract: a review. J Cell Mol Med 2001;5:327-51.

5 Taylor-Papadimitriou J, Burchell JM, Plunkett T, et al. MUC1 and the immunobiology of cancer. J Mammary Gland Biol Neoplasia 2002; 7:209-21

6 Chen Y, Zhao YH, Kalaslavadi TB, et al. Genome-wide search and identification of a novel gel-forming mucin MUC19/Muc19 in glandular tissues. Am J Respir Cell Mol Biol 2004;30:155-65.

7 Ringel J, Lohr M. The MUC gene family: their role in diagnosis and early detection of pancreatic cancer. Mol Cancer 2003;2:9.

8 Yin L, Li Y, Ren J, et al. Human MUC1 carcinoma antigen regulates intracellular oxidant levels and the apoptotic response to oxidative stress. $J$ Biol Chem 2003;278:35458-64.

9 Li Y, Kufe D. The Human DF3/MUC1 carcinoma-associated antigen signals nuclear localization of the catenin p120(ctn). Biochem Biophys Res Commun 2001;281:440-3.

10 Yamamoto $M$, Bharti A, Li Y, et al. Interaction of the DF3/MUCl breast carcinoma-associated antigen and beta-catenin in cell adhesion. $J$ Biol Chem 1997;272:12492-4

11 Buisine MP, Devisme L, Degand P, et al. Developmental mucin gene expression in the gastroduodenal tract and accessory digestive glands. II. Duodenum and liver, gallbladder, and pancreas. J Histochem Cytochem 2000;48: 1667-76.

12 Lee MJ, Lee HS, Kim WH, et al. Expression of mucins and cytokeratins in primary carcinomas of the digestive system. Mod Pathol 2003;16:403-10.

13 Andrianifahanana M, Moniaux N, Schmied BM, et al. Mucin (MUC) gene expression in human pancreatic adenocarcinoma and chronic pancreatitis: a potential role of MUC4 as a tumor marker of diagnostic significance. Clin Cancer Res 2001;7:4033-40.

14 Terada T, Ohta T, Sasaki M, et al. Expression of MUC apomucins in normal pancreas and pancreatic tumours. J Pathol 1996;180:160-5.

15 Masaki Y, Oka M, Ogura Y, et al. Sialylated MUC1 mucin expression in normal pancreas, benign pancreatic lesions, and pancreatic ductal adenocarcinoma. Hepatogastroenterology 1999;46:2240-5.

16 Terris B, Dubois S, Buisine MP, et al. Mucin gene expression in intraductal papillary-mucinous pancreatic tumours and related lesions. J Pathol 2002; 197:632-7.

17 Yonezawa S, Horinouchi M, Osako M, et al. Gene expression of gastric type mucin (MUC5AC) in pancreatic tumors: its relationship with the biological behavior of the tumor. Pathol Int 1999;49:45-54.

18 Allen A, Hutton DA, Pearson JP. The MUC2 gene product: a human intestinal mucin. Int J Biochem Cell Biol 1998;30:797-801.

19 Van Klinken BJ, Tytgat KM, Buller HA, et al. Biosynthesis of intestinal mucins: MUC1, MUC2, MUC3 and more. Biochem Soc Trans 1995;23:814-18.

$20 \mathrm{Kim}$ YS, Gum JR Jr, Byrd JC, et al. The structure of human intestinal apomucins. Am Rev Respir Dis 1991; 144:S10-14.

21 Yonezawa S, Sato E. Expression of mucin antigens in human cancers and its relationship with malignancy potential. Pathol Int 1997;47:813-30.

22 Van De Bovenkamp JH, Korteland-Van Male AM, Warson C, et al. Gastric-type mucin and TFF-peptide expression in Barrett's oesophagus is disturbed during increased expression of MUC2. Histopathology 2003;42:555-65.

23 Warson C, Van De Bovenkamp JH, Korteland-Van Male AM, et al. Barrett's esophagus is characterized by expression of gastric-type mucins (MUC5AC, MUC6) and TFF peptides (TFF1 and TFF2), but the risk of carcinoma development may be indicated by the intestinal-type mucin, MUC2. Hum Pathol 2002;33:660-8.

24 Siedow A, Szyf M, Gratchev A, et al. De novo expression of the Muc2 gene in pancreas carcinoma cells is triggered by promoter demethylation. Tumour Biol 2002;23:54-60.

$25 \mathrm{Kim}$ YS, Gum J Jr, Brockhausen I. Mucin glycoproteins in neoplasia. Glycoconj J 1996;13:693-707.

26 Li Y, Chen W, Ren J, et al. DF3/MUC1 signaling in multiple myeloma cells is regulated by interleukin-7. Cancer Biol Ther 2003;2:187-93.

27 Pandey P, Kharbanda S, Kufe D. Association of the DF3/MUC1 breast cancer antigen with Grb2 and the Sos/Ras exchange protein. Cancer Res 1995;55:4000-3.

28 Li Y, Ren J, Yu W, et al. The epidermal growth factor receptor regulates interaction of the human DF3/MUC1 carcinoma antigen with c-Src and betacatenin. J Biol Chem 2001;276:35239-42.

29 Ren J, Li Y, Kufe D. Protein kinase C delta regulates function of the DF3/ $\mathrm{MUCl}$ carcinoma antigen in beta-catenin signaling. $J \mathrm{Biol}$ Chem 2002;277:17616-22.

30 Li Y, Kuwahara H, Ren J, et al. The c-Src tyrosine kinase regulates signaling of the human DF3/MUC1 carcinoma-associated antigen with GSK3 beta and beta-catenin. J Biol Chem 2001;276:6061-4.

31 Wen Y, Caffrey TC, Wheelock MJ, et al. Nuclear association of the cytoplasmic tail of MUC1 and (beta)-catenin. J Biol Chem 2003.

32 Tamada S, Goto M, Nomoto M, et al. Expression of MUC1 and MUC2 mucins in extrahepatic bile duct carcinomas: its relationship with tumor progression and prognosis. Pathol Int 2002;52:713-23. 
33 Yonezawa S, Nakamura A, Horinouchi M, et al. The expression of several types of mucin is related to the biological behavior of pancreatic neoplasms. $J$ Hepatobiliary Pancreat Surg 2002;9:328-41.

34 Akyurek N, Akyol G, Dursun A, et al. Expression of MUC1 and MUC2 mucins in gastric carcinomas: their relationship with clinicopathologic parameters and prognosis. Pathol Res Pract 2002; 198:665-74.

35 Sivridis E, Giatromanolaki A, Koukourakis MI, et al. Patterns of episialin/ MUC1 expression in endometrial carcinomas and prognostic relevance. Histopathology 2002;40:92-100.

36 Kraus S, Abel PD, Nachtmann C, et al. MUC1 mucin and trefoil factor 1 protein expression in renal cell carcinoma: correlation with prognosis. Hum Pathol 2002;33:60-7.

37 Hanson JM, Browell DA, Cunliffe WJ, et al. MUC1 expression in primary breast cancer: the effect of tamoxifen treatment. Breast Cancer Res Treat $2001 ; 67: 215-22$.

38 Lee HS, Lee HK, Kim HS, et al. MUC1, MUC2, MUC5AC, and MUC6 expressions in gastric carcinomas: their roles as prognostic indicators. Cancer 2001;92:1427-34.

39 Paydas S, Sahin B, Gonlusen G, et al. MUCl expression in plasmacytoma. Leuk Res $2001 ; 25: 221-5$

40 Manne U, Weiss HL, Grizzle WE. Racial differences in the prognostic usefulness of $\mathrm{MUC1}$ and MUC2 in colorectal adenocarcinomas. Clin Cancer Res 2000;6:4017-25.

41 Guddo F, Giatromanolaki A, Koukourakis MI, et al. MUC1 (episialin) expression in non-small cell lung cancer is independent of EGFR and c-erbB2 expression and correlates with poor survival in node positive patients. J Clin Pathol 1998:51:667-71.

42 Takao S, Uchikura K, Yonezawa S, et al. Mucin core protein expression in extrahepatic bile duct carcinoma is associated with metastases to the liver and poor prognosis. Cancer 1999;86:1966-75.

43 McGuckin MA, Walsh MD, Hohn BG, et al. Prognostic significance of $\mathrm{MUC1}$ epithelial mucin expression in breast cancer. Hum Pathol 1995;26:432-9.

44 Rassidakis GZ, Goy A, Medeiros $\amalg$, et al. Prognostic significance of MUC-1 expression in systemic anaplastic large cell lymphoma. Clin Cancer Res 2003;9:2213-20.

45 Kohlgraf KG, Gawron AJ, Higashi M, et al. Contribution of the MUC1 tandem repeat and cytoplasmic tail to invasive and metastatic properties of a pancreatic cancer cell line. Cancer Res 2003;63:501 1-20.

46 Velcich A, Yang W, Heyer J, et al. Colorectal cancer in mice genetically deficient in the mucin Muc2. Science 2002;295:1726-9.

47 Silberg DG, Swain GP, Suh ER, et al. Cdx1 and cdx2 expression during intestinal development. Gastroenterology 2000;1 19:961-71.

48 Eda A, Osawa H, Yanaka I, et al. Expression of homeobox gene CDX2 precedes that of $C D X 1$ during the progression of intestinal metaplasia. J Gastroenterol 2002;37:94-100.

49 Yamamoto H, Bai YQ, Yuasa Y. Homeodomain protein CDX2 regulates goblet-specific MUC2 gene expression. Biochem Biophys Res Commun 2003;300:813-18.

50 Seno $\mathrm{H}$, Oshima M, Taniguchi MA, et al. CDX2 expression in the stomach with intestinal metaplasia and intestinal-type cancer: prognostic implications. Int J Oncol 2002;21:769-74.

51 Silberg DG, Sullivan J, Kang E, et al. Cdx2 ectopic expression induces gastric intestinal metaplasia in transgenic mice. Gastroenterology 2002; 122:689-96

52 Almeida R, Silva E, Santos-Silva F, et al. Expression of intestine-specific transcription factors, $C D X 1$ and $C D X 2$, in intestinal metaplasia and gastric carcinomas. J Pathol 2003;199:36-40.

53 Eda A, Osawa H, Satoh K, et al. Aberrant expression of CDX2 in Barrett's epithelium and inflammatory esophageal mucosa. J Gastroenterol 2003;38: 14-22.

54 Yuasa $Y$. Control of gut differentiation and intestinal-type gastric carcinogenesis. Nat Rev Cancer 2003;3:592-600.

55 Ookawa K, Kudo T, Aizawa S, et al. Transcriptional activation of the MUC2 gene by p53. J Biol Chem 2002;277:48270-5.

56 Oren M. Decision making by p53: life, death and cancer. Cell Death Differ 2003; 10:431-42.

57 Conio M, Lapertosa G, Blanchi S, et al. Barrett's esophagus: an update. Crit Rev Oncol Hematol 2003;46:187-206.

58 Walker MM. Is intestinal metaplasia of the stomach reversible? Gut 2003;52:1-4.

59 Hanski C, Riede E, Gratchev A, et al. MUC2 gene suppression in human colorectal carcinomas and their metastases: in vitro evidence of the modulatory role of DNA methylation. Lab Invest 1997;77:685-95.

60 Jang KT, Chae SW, Sohn JH, et al. Coexpression of MUC1 with p53 or MUC2 correlates with lymph node metastasis in colorectal carcinomas. J Korean Med Sci 2002;17:29-33.

61 Ho SB, Niehans GA, Lyftogt C, et al. Heterogeneity of mucin gene expression in normal and neoplastic tissues. Cancer Res 1993;53:641-51.

62 Caderni G, Femia AP, Giannini A, et al. Identification of mucin-depleted foci in the unsectioned colon of azoxymethane-treated rats: correlation with carcinogenesis. Cancer Res 2003;63:2388-92.

63 Velcich A, Palumbo L, Selleri L, et al. Organization and regulatory aspects of the human intestinal mucin gene (MUC2) locus. J Biol Chem 1997:272:7968-76.

$64 \mathrm{Ho} \mathrm{JJ}$, Han SW, Pan PL, et al. Methylation status of promoters and expression of MUC2 and MUC5AC mucins in pancreatic cancer cells. Int J Oncol 2003;22:273-9

65 Van Seuningen I, Pigny $P$, Perrais $M$, et al. Transcriptional regulation of the 11 p15 mucin genes. Towards new biological tools in human therapy, in inflammatory diseases and cancer? Front Biosci $2001 ; 6$ :D1216-34.
66 Adsay NV, Merati K, Andea A, et al. The dichotomy in the preinvasive neoplasia to invasive carcinoma sequence in the pancreas: differential expression of $\mathrm{MUC1}$ and MUC2 supports the existence of two separate pathways of carcinogenesis. Mod Pathol 2002;15:1087-95.

67 Luttges J, Feyerabend B, Buchelt $\mathrm{T}$, et al. The mucin profile of noninvasive and invasive mucinous cystic neoplasms of the pancreas. Am J Surg Pathol 2002;26:466-71

68 Hruban RH, Adsay NV, Albores-Saavedra J, et al. Pancreatic intraepithelial neoplasia: a new nomenclature and classification system for pancreatic duct lesions. Am J Surg Pathol 2001;25:579-86.

69 Parsa I, Longnecker DS, Scarpelli DG, et al. Ductal metaplasia of human exocrine pancreas and its association with carcinoma. Cancer Res 1985:45:1285-90.

70 Bastid C, Bernard JP, Sarles H, et al. Mucinous ductal ectasia of the pancreas: a premalignant disease and a cause of obstructive pancreatitis. Pancreas 1991;6:15-22.

71 Schulz HJ. [Dysplasia and carcinoma in situ of the pancreatic duct epithelium.] Zentralbl Allg Pathol, 1988;134:3-14.

72 Traverso LW, Peralta EA, Ryan JA Jr, et al. Intraductal neoplasms of the pancreas. Am J Surg 1998;175:426-32.

73 Adsay NV, Adair CF, Heffess CS, et al. Intraductal oncocytic papillary neoplasms of the pancreas. Am J Surg Pathol 1996;20:980-94

74 Maire F, Hammel P, Terris B, et al. Intraductal papillary and mucinous pancreatic tumour: a new extracolonic tumour in familial adenomatous polyposis. Gut 2002;51:446-9.

75 Yeo CJ. Intraductal papillary mucinous neoplasms of the pancreas. Adv Surg 2002;36:15-38

76 Farrell JJ, Brugge WR. Intraductal papillary mucinous tumor of the pancreas. Gastrointest Endosc 2002;55:701-14.

77 Siech M, Tripp K, Schmidt-Rohlfing B, et al. Intraductal papillary mucinous tumor of the pancreas. Am J Surg 1999;177:117-20.

78 Tollefson MK, Libsch KD, Sarr MG, et al. Intraductal papillary mucinous neoplasm: did it exist prior to 1980? Pancreas 2003:26:E55-8.

79 Van de Stadt J, Closset J, Gelin M. Intraductal papillary mucinous tumors (IPMT). Ann Surg 1999;230:828-9

80 Baek IS, Jeong AC, Lee SB, et al. A case of intraductal papillary tumor of pancreas associated with mucinous ductal ectasia. Korean J Intern Med 1997; 12:100-4.

81 Fukushima N, Mukai K, Kanai Y, et al. Intraductal papillary tumors and mucinous cystic tumors of the pancreas: clinicopathologic study of 38 cases. Hum Pathol 1997:28:1010-17.

82 Kobayashi G, Fujita N, Noda Y, et al. [Study of cases of mucin producing tumors of the pancreas showing penetration into other organs.] Nippon Shokakibyo Gakkai Zasshi 1993;90:3081-9

83 Mukai H, Yasuda K, Nakajima M. Differential diagnosis of mucin-producing tumors of the pancreas by intraductal ultrasonography and peroral pancreatoscopy. Endoscopy 1998;30(suppl 1):A99-102.

84 Scott J, Martin I, Redhead D, et al. Mucinous cystic neoplasms of the pancreas: imaging features and diagnostic difficulties. Clin Radiol 2000:55: 187-92.

85 Kloppel G, Kosmahl M. Cystic lesions and neoplasms of the pancreas. The features are becoming clearer. Pancreatology 2001;1:648-55.

86 Lichtenstein DR, Carr-Locke DL. Mucin-secreting tumors of the pancreas. Gastrointest Endosc Clin North Am 1995;5:237-58.

87 Adsay NV, Conlon KC, Zee SY, et al. Intraductal papillary-mucinous neoplasms of the pancreas: an analysis of in situ and invasive carcinomas in 28 patients. Cancer 2002;94:62-77.

88 Adsay NV, Longnecker DS, Klimstra DS. Pancreatic tumors with cystic dilatation of the ducts: intraductal papillary mucinous neoplasms and intraductal oncocytic papillary neoplasms. Semin Diagn Pathol 2000; 17:16-30

89 Barbe L, Ponsot P, Vilgrain V, et al. [Intraductal papillary mucinous tumors of the pancreas. Clinical and morphological aspects in 30 patients.] Gastroenterol Clin Biol 1997;21:278-86.

90 Adsay NV. Intraductal papillary mucinous neoplasms of the pancreas: pathology and molecular genetics. J Gastrointest Surg 2002:6:656-9

91 Al-Sukhun S, Hussain M. Molecular biology of transitional cell carcinoma. Crit Rev Oncol Hematol 2003;47:181-93.

92 Lefkowitz M, Lefkowitz W, Wargotz ES. Intraductal (intracystic) papillary carcinoma of the breast and its variants: a clinicopathological study of 77 cases. Hum Pathol 1994;25:802-9.

93 Markopoulos C, Kouskos E, Gogas H, et al. Diagnosis and treatment of intracystic breast carcinomas. Am Surg 2002;68:783-6.

94 Tsuda H, Fukutomi T, Hirohashi S. Pattern of gene alterations in intraducta breast neoplasms associated with histological type and grade. Clin Cancer Res 1995; 1:261-7.

95 Luttges J, Zamboni G, Longnecker D, et al. The immunohistochemical mucin expression pattern distinguishes different types of intraductal papillary mucinous neoplasms of the pancreas and determines their relationship to mucinous noncystic carcinoma and ductal adenocarcinoma. Am J Surg Pathol 2001;25:942-8.

96 Luttges J, Beyser K, Pust S, et al. Pancreatic mucinous noncystic (colloid) carcinomas and intraductal papillary mucinous carcinomas are usually microsatellite stable. Mod Pathol 2003; 16:537-42

97 Kloppel G, Luttges J. WHO-classification 2000: exocrine pancreatic tumors. Verh Dtsch Ges Pathol $2001 ; 85: 219-28$.

98 Monges GM, Mathoulin-Portier MP, Acres RB, et al. Differential MUC 1 expression in normal and neoplastic human pancreatic tissue. An 
immunohistochemical study of 60 samples. Am J Clin Pathol 1999; 112:635-40

99 Adsay NV, Pierson C, Sarkar F, et al. Colloid (mucinous noncystic) carcinoma of the pancreas. Am J Surg Pathol 2001;25:26-42.

100 Adsay NV, Merati K, Nassar H, et al. Pathogenesis of colloid (pure mucinous) carcinoma of exocrine organs: coupling of gel-forming mucin (MUC2) production with altered cell polarity and abnormal cell-stroma interaction may be the key factor in the morphogenesis and indolent behavior of colloid carcinoma in the breast and pancreas. Am J Surg Pathol 2003;27:571-8.

101 Fischer HP, Zhou H. [Pathogenesis and histomorphology of ampullary carcinomas and their precursor lesions. Review and individual findings.] Pathologe 2003:24:196-203.

102 Kitamura H, Yonezawa S, Tanaka S, et al. Expression of mucin carbohydrates and core proteins in carcinomas of the ampulla of Vater: their relationship to prognosis. Jpn J Cancer Res 1996;87:631-40.

\section{Clinical Evidence - Call for contributors}

Clinical Evidence is a regularly updated evidence based journal available worldwide both as a paper version and on the internet. Clinical Evidence needs to recruit a number of new contributors. Contributors are health care professionals or epidemiologists with experience in evidence based medicine and the ability to write in a concise and structured way.

\section{Currently, we are interested in finding contributors with an interest in} the following clinical areas:

Altitude sickness; Autism; Basal cell carcinoma; Breast feeding; Carbon monoxide poisoning; Cervical cancer; Cystic fibrosis; Ectopic pregnancy; Grief/bereavement; Halitosis; Hodgkins disease; Infectious mononucleosis (glandular fever); Kidney stones; Malignant melanoma (metastatic); Mesothelioma; Myeloma; Ovarian cyst; Pancreatitis (acute); Pancreatitis (chronic); Polymyalgia rheumatica; Post-partum haemorrhage; Pulmonary embolism; Recurrent miscarriage; Repetitive strain injury; Scoliosis; Seasonal affective disorder; Squint; Systemic lupus erythematosus; Testicular cancer; Varicocele; Viral meningitis; Vitiligo However, we are always looking for others, so do not let this list discourage you.

Being a contributor involves:

- Appraising the results of literature searches (performed by our Information Specialists) to identify high quality evidence for inclusion in the journal.

- Writing to a highly structured template (about 2000-3000 words), using evidence from selected studies, within 6-8 weeks of receiving the literature search results.

- Working with Clinical Evidence Editors to ensure that the text meets rigorous epidemiological and style standards.

- Updating the text every eight months to incorporate new evidence.

- Expanding the topic to include new questions once every 12-18 months.

If you would like to become a contributor for Clinical Evidence or require more information about what this involves please send your contact details and a copy of your CV, clearly stating the clinical area you are interested in, to Claire Folkes (cfolkes@bmigroup.com).

\section{Call for peer reviewers}

Clinical Evidence also needs to recruit a number of new peer reviewers specifically with an interest in the clinical areas stated above, and also others related to general practice. Peer reviewers are health care professionals or epidemiologists with experience in evidence based medicine. As a peer reviewer you would be asked for your views on the clinical relevance, validity, and accessibility of specific topics within the journal, and their usefulness to the intended audience (international generalists and health care professionals, possibly with limited statistical knowledge). Topics are usually 2000-3000 words in length and we would ask you to review between 2-5 topics per year. The peer review process takes place throughout the year, and our turnaround time for each review is ideally 10-14 days.

If you are interested in becoming a peer reviewer for Clinical Evidence, please complete the peer review questionnaire at www.clinicalevidence.com or contact Claire Folkes(cfolkes@bmigroup.com). 


\section{PostScript}

\section{CORRESPONDENCE}

If you have a burning desire to respond to a paper published in the Journal of Clinical Pathology, why not make use of our "rapid response" option?

Log on to our website (www.jclinpath. com), find the paper that interests you, and send your response via email by clicking on the "eletters" option in the box at the top right hand corner.

Providing it isn't libellous or obscene, it will be posted within seven days. You can retrieve it by clicking on "read eletters" on our homepage.

The editors will decide as before whether to also publish it in a future paper issue.

\section{Cancer stem cell theory: pathologists' considerations and ruminations about wasting time and wrong evaluations}

The genomic revolution has changed the role of the pathologist. In daily practice, our work is no longer limited to reaching a correct diagnosis and we are asked to answer questions about the patient's prognosis and treatment options through the evaluation of selected molecular targets (such as erbB2 for breast cancer) in tumour specimens. Thus, we have acquired a major role in the translation of novel gene findings from experimental model systems to their clinical application.

There is overwhelming evidence that only a subset of cells within a tumour clone, referred to as cancer stem cells, are tumorigenic and possess the metastatic phenotype. The recent identification of human breast cancer initiating cells by Al-Hajj and colleagues $^{2}$ provided a major step forward in this field. With this knowledge, the stem cell compartment should represent the selected target for tumour eradication.

As pathologists we would like to share some considerations and ruminations about this scenario.

Currently, tissue microarray analysis generates gene profiles capable of differentiating tumours with different biological behaviours. ${ }^{3}$ However, this screening method is conducted on heterogeneous tumour tissue samples containing a mixture of non-neoplastic cells, non-tumorigenic cancer cells, and cancer stem cells. Similarly, until now, we have evaluated the immunohistochemical expression of a molecular marker in the bulk of the tumour, considering it as relatively homogeneous.

What is the clinical relevance of these results? Although new therapeutic approaches based on these studies have modified the prognosis of some neoplasms, ${ }^{4}$ conflicting results are still seen with many other tumours. ${ }^{5}$ We should start to feel worried about the value of the information retrieved from this type of tumour analysis.
The few cancer stem cells and the large number of cells constituting the tumour are morphologically similar but functionally heterogeneous. It is likely that we are still evaluating the main population of tumour cells, which are not cancer stem cells, and are thus probably wasting time and loosing essential treatment information. It is unlikely that gene expression profiles obtained using the currently available methods reflect those of the tumour stem cell population, which forms only $0.1-2 \%$ of the whole tissue sample. ${ }^{126}$

The cancer stem cell hypothesis has started a new era in cancer research. Tumours contain functionally different subpopulations of cells. However, unique gene expression profiles are generated by current methods of evaluation. Probably, when the isolation and molecular characterisation of cancer stem cells from primary tissue becomes possible, the role of pathologists will change again. Collaboration between researchers and pathologists will be more widely practised and we will be able to rise to the next challenge; namely, assessing the prognosis of a patient from only one of 5000 tumour cells in a tissue sample.

P Nuciforo

Fimo-Firc Institute of Molecular Pathology Via Adamello 16, Milano 20139, Italy nuciforo@ifom-firc.it

F Fraggetta

Azienda Ospedaliera Cannizzaro, Via Messina, 829, Catania 95126 , Italy

\section{References}

1 Reya T, Morrison SJ, Clarke MF, et al. Stem cells, cancer, and cancer stem cells. Nature 2001:414:105-11.

2 Al-Haii M, Wicha MS, Benito-Hernandez A, et al. Prospective identification of tumorigenic breast cancer cells. Proc Natl Acad Sci U S A 2003;100:3983-8.

3 Van de Vijuer MJ, He YD, van't Veer $\sqcup$, et al. A gene-expression signature as a predictor of survival in breast cancer. N Engl I Med 2002;347:1999-2009.

4 Orr MS, Scherf U. Large-scale gene expression analysis in molecular target discovery. Leukemia 2002;16:473-7.

5 Carney DN. Lung cancer-time to move on from chemotherapy. N Engl I Med 2002;346:126-8.

6 Dick JH. Breast cancer stem cells revealed. Proc Natl Acad Sci U S A 2003;100:3547-9.

\section{Public opinion on the use of tissue samples}

I read with interest and increasing concern the paper by Goodson and Vernon, " "A study of public opinion on the use of tissue samples from living subjects for clinical research". The paper demonstrates that the use of a vaguely worded and ambiguous questionnaire leads to misleading results. A few of the problems with the questions may be taken individually:

(1) "Would you be happy for pieces of any of the following body tissues or organs to be used in clinical research? (Eyes, lung, heart, tissue from head and neck, embryo, brain, ovary, testes, bone, and breast.)"
The question could refer to postmortem tissue and the choice of organs is (as the authors confess) deliberately "emotional", with no insight into every day pathological services. Heart, brain, and eyes are not exactly common surgical specimens, whereas embryos are subject to special guidelines. Surely, this question is almost designed to make the patient believe it refers to postmortem organs? The use of subjective words such as "happy" is extremely unhelpful. "Are you happy to vote Labour?" would not, for example, be acceptable in a comparable political survey!

(2) "What kind of research would you be happy for your tissues to be used for? (Cancer research, testing medicines, genetic cloning, general knowledge of body tissues, genetic research for diagnosis or treatment of, for example, Down's syndrome.)"

Again scientific imprecision exists, because the writers of the questionnaire appear not to understand that these fields are interdependent. In particular, the lack of public understanding of cloning has caused them to reject this field, with no idea that this may include tissue culture or polymerase chain reaction

(3) "Would you want to be informed if your tissues were to be stored beyond the time required for diagnosis?"

This question seems to show no knowledge of the necessity for longterm storage of samples after diagnosis. Tissue retention for medicolegal, audit, clinical governance, and comparison with later samples has been ignored. No explanation has been given to the patients of why this is in their best interests.

(4) "Would you be happy to give consent for a child's tissues to be used for scientific research?"

Apart from the obvious flaw that it has not been stated whose child is being talked about, again the question appears almost deliberately ambiguous and could be taken to refer to postmortem tissue. Apparently, the designers of the questionnaire are interested in "scientific research" on children's tissues, whereas in adults in question $l$ it is only "clinical research".

(5) "Would you be happy to give consent for your tissues to be used to teach medical students?"

The word happy is used again, in addition to a lack of explanation of how the tissues are "used", and the vital role of histology in teaching medical students and pathology trainees.

I suggest to the authors that their survey, in contrast to all other studies, shows that patients were unwilling to donate their tissues because they were presented with a poorly designed, misleading survey.

D M Berney

Department of Pathology, St Bartholomew's Hospital, West Smithfield, London EClA 7BE, UK; danberney@hotmail.com 


\section{Reference}

1 Goodson ML, Vernon BG. A study of public opinion on the use of tissue samples from living subjects for clinical research. J Clin Pathol 2004:57:135-8.

\section{Authors' response}

We are grateful for the opportunity to respond to Dr Berney's letter. The questionnaire used in our study was piloted on a similar group of respondents. The patient information leaflet and consent form given and explained before completion of the questionnaire made it clear that we were only concerned with tissue donated by living subjects for research and did not refer to the use of postmortem specimens or tissue or organs for transplantation. In addition, all respondents were given the opportunity to ask questions before completing the questionnaire if they were unsure of the meaning of any questions.

We imagine that many of the research fields are interdependent, although the general public may not be aware of this. Our study did not attempt to explain why respondents answered questions in any particular way, but it shows that people may or may not be willing to donate different types of tissue for different types of research. This may be because of a lack of understanding of the clinical and laboratory techniques used in research, but we have not attempted to prove this in our study.

We agree that no explanation was given to respondents (who were not patients) about the benefits of retention of tissue samples; this would have biased the response.

Dr Berney says that our question surrounding consenting for donation of a child's tissue for research is flawed because it does not explain whose child we are discussing. Our pilot study demonstrated that the phrase "your child" eliminated responses from childless adults, adults with children over 16 years of age who were able to consent for themselves, and individuals who had children, but for various reasons were no longer the guardians of such children. The question merely attempted to identify whether or not there was some reluctance by adults to consent for children.

Our research showed a snap shot of public attitudes to tissue donation from living subjects for clinical research and offers no more than an indicator of public attitude, and like most research requires further qualification.

We are grateful to Dr Berney for his comments because they open up the debate on whether the public accepts tissue donation for research purposes. To restore public confidence in the medical profession and research in general, it is crucial for the profession to take account of public perceptions and to understand the nature of the explanations that are required

M L Goodson, B G Vernon School of Population and Health Science, University of Newcastle, Newcastle upon Tyne, NE2 4HH M.L.Goodson@ncl.ac.uk

\section{Limitations of the Wilcoxon matched pairs signed ranks test for comparison studies}

We read the short report by Ellis et al with interest. ${ }^{1}$ However, we are unsure whether they have adequately proved that no significant difference was detected between the two outlined storage methods.

The hypothesis evaluated with the Wilcoxon matched pairs signed ranks test is whether or not the median of the difference scores equals zero. Let us consider the situation of $x$ measurements tending to exceed $y$ measurements in the low range and vice versa in the high range, with similar values in the mid range. Such results may have a median of the difference scores of approximately zero; that is, there might be no significant differences by the Wilcoxon matched pairs signed ranks test, although there would be differences by linear regression (Deming or Passing-Bablok) and/or difference plots.

However, this short report ${ }^{1}$ lacks both a regression equation (proportional and constant error) and difference plots. Therefore, we believe that although the IgG anti-rubella activity in frozen serum stored in primary gel separation tubes may not be significantly different from that stored frozen in secondary tubes, this study did not sufficiently prove this. We recommend, in line with others, ${ }^{2}$ that difference plots ${ }^{3}$ are used for such comparative studies and that such studies are put into a clinical context. ${ }^{34}$

P J Twomey

Department of Clinical Biochemistry, The Ipswich Hospital, Heath Road, Ipswich IP4 5PD, UK taptwomey@aol.com

A Viljoen

Department of Clinical Biochemistry, Royal Infirmary of Edinburgh, Room S6114 Level 2, 51 Little France Crescent, Edinburgh EH16 4SA, UK

\section{References}

1 Ellis V, Charlett A, Bendall R. A comparison of lgG anti-rubella activity in frozen serum stored in primary gel separation tubes or secondary tubes. $J$ Clin Pathol 2004;57:104-6.

2 Hollis S. Analysis of method comparison studies. Ann Clin Biochem 1996:33:1-4.

3 Bland JM, Altman DG. Statistical methods for assessing agreement between two methods of clinical measurement. Lancet 1986;i:307-10.

4 Fraser CG, Kallner A, Kenny D, et al. Introduction: strategies to set global quality specifications in laboratory medicine. Scand J Clin Lab Invest 1999;59:477-8

\section{BOOK REVIEWS}

\section{Basic Pathology: An Introduction to the Mechanisms of Disease}

Lakhani S R, Dilly S A, Finlayson C J, et al. (£22.99.) Arnold, 2003. ISBN 0340810017.

With the new "integrated" undergraduate medical curriculum being adopted by medical schools in many countries, there is an ever increasing need for an appropriate basic pathology textbook. The authors have produced a book which is based on the principles and objectives of the integrated curriculum. Consequently, it is an ideal basic pathology textbook for students in the integrated medical curriculum.

The book has a novel approach to basic pathology, which is different from the standard basic pathology textbooks. There are four parts: "Introduction-what is a disease?", "Defence against disease", "Circulatory disorders", and "Disorders of cell growth". Each part consists of a variable number of chapters containing several unique learning aids.

The material is presented in a format that is easy to read and can be read at leisure. In accordance with the integrated curriculum, some material is presented by using clinical cases-for example, myocardial infarction, breast lump, and prostatic hyperplasia, among others. Innovative additions are the excellent cartoons, selected "key facts", "dictionary box", and "small print". The cartoons are well illustrated, extremely apt, and informative. There is also a selection of relevant tables that complement the text. The inclusion of appropriate colour diagrams, photomicrographs, and macroscopic pathology images aids the text. Clinicopathological case studies are used as a tool to facilitate the integration of pathology with clinical medicine. At the end of each part, there is a selection of questions covering core material with answers and cross references.

There are six colour coded theme maps that cover the four main pathology disciplineshistopathology, haematology, immunology, and microbiology - and two additional overview themes-science and disease and patient and disease.

The authors have produced a remarkable book, which deals with a difficult but important subject in a user friendly manner. The book ought to be prescribed reading for undergraduate students in the new integrated medical curriculum.

D Govender

\section{The Cytology of Soft Tissue Tumours}

Akerman M, Domanski H A. (€110.00.) Karger, 2003. ISBN 380557597.

Åkerman's and Domanski's text The Cytology of Soft Tissue Tumours from the Monographs in Clinical Cytology series is a beautifully illustrated, well referenced and written treatise on the interpretation of fine needle aspirations (FNAs) of these lesions. The text starts with a brief overview of the FNA of soft tissue tumours including accuracy, pitfalls, complications, and a discussion of the aspiration technique itself, with application of ancillary studies. This is followed by a concise review of the specific entities following standard histogenetic organisation. With each major entity, the salient cytological features and differential diagnostic considerations are clearly listed, with comments on the potential pitfalls admixed with helpful hints, providing a practical approach to the diagnosis of the lesions. The final chapter summarises in tabular form the salient diagnostic features and results of ancillary studies of the various entities in groupings based on a pattern recognition approach. Illustrations abound and include air dried May-Grünwald-Giemsa, in addition to alcohol fixed haematoxylin and eosin or occasionally Papanicolaou stained cytological preparations. Little criticism of this text can be found and there is no question that this book should be in the library of those interpreting FNAs of soft tissue lesions.

S Boerner 


\section{CALENDAR OF EVENTS}

Full details of events to be included should be sent to Maggie Butler, Technical Editor JCP. The Cedars, 36 Queen Street, Castle Hedingham, Essex CO9 3HA, UK; email: maggie.butler2@btopenworld.com

\section{Practical Pulmonary Pathology}

27-30 July, 2004, Brompton Hospital, London, UK

Further details: Professor B Corrin, Brompton Hospital, London SW3 6NP, UK. (Tel: +44 (0)20 7351 8420; Fax: +44 (0)20 7351 8293; Email: b.corrin@ic.ac.uk)

\section{ACP Management Course for} Pathologists, 2004

8-10 September 2004, Hardwick Hall Hotel, Sedgefield, County Durham, UK

Further details: V Wood, ACP Central Office, 189 Dyke Road, Hove, East Sussex BN3 ITL, UK. (Tel: +44 (0) 1273 775700; Fax: +44 (0) 1273 773303; Email: Jacqui@pathologists.org.uk)
Combined Adult and Congenital Cardiovascular Pathology Course

8-10 November 2004, Imperial School of Medicine, National Heart and Lung Institute, London, UK

Further details: Short Course Office, National Heart and Lung Institute, Dovehouse Street, London SW3 6LY, UK (Tel: +44 (0)20 7351 8172; Fax: +44 (0)20 7351 8246; Email: shourtcourse.NHLI@ IC.AC.UK)

Asian Pacific Association for Study of the Liver Biennial Conference

11-15 December 2004, New Delhi, India Further details: Dr V Malhotra (General Secretary) or Dr P Sakhuja (Treasurer and Pathology Coordinator), Room 325, Academic Block, Department of Pathology, GB Pant Hospital, New Delhi 110002 India. (Tel: +91 11 23237455; Email: welcome@apaslindia2004.com; Website: www.apaslindia2004.com)

\section{CORRECTIONS}

MUC1 and MUC2 in pancreatic neoplasia. E Levi, D S Klimstra, N V Adsay, A Andrea, O Basturk. J Clin Pathol 2004;

57:456-62. The order of the authors should be E Levi, D S Klimstra, A Andrea, O Basturk, $\mathrm{N}$ V Adsay.

Urinary catecholamines and metabolites in the immediate postoperative period following major surgery. Dr A A Syed, $\mathrm{H}$ A Wheatley, $\mathrm{M} \mathrm{N}$ Badminton, et al. $J$ Clin Pathol 2004;57:548-50. The first author's name should be A A Syed.

Focal nodular hyperplasia with concomitant hepatocellular carcinoma: a case report and clonal analysis. S-H Zhang, W-M Cong, M-C Wu. J Clin Pathol 2004 57:556-9. The image shown in fig 2 should have been fig 3 and vice versa. 